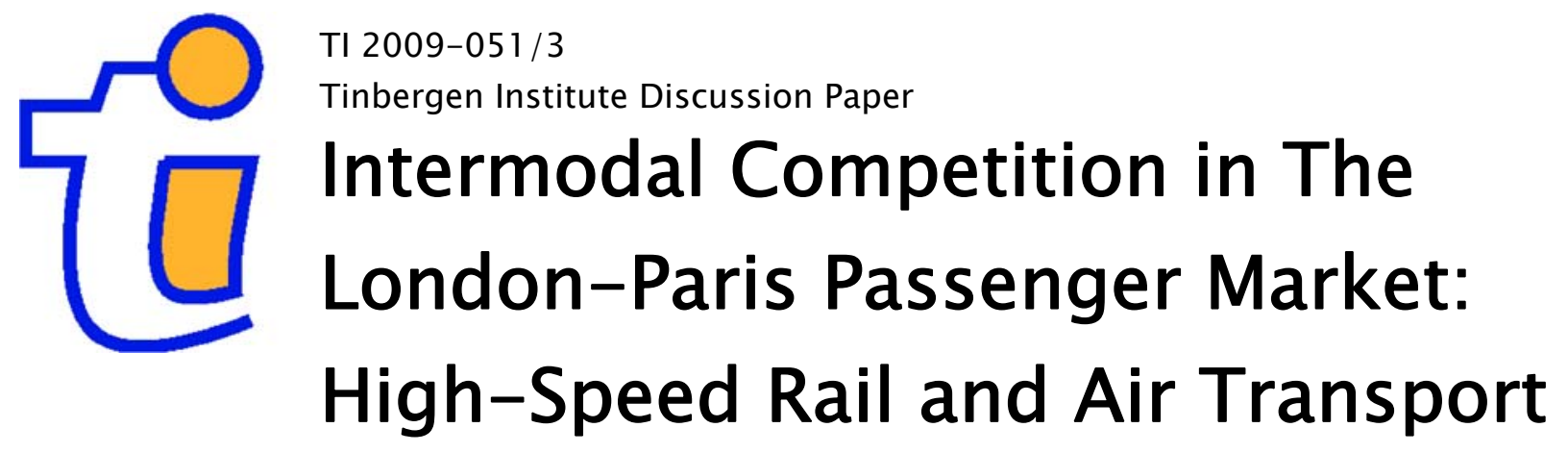

Christiaan Behrens

Eric Pels*

Dept. of Spatial Economics, University of Amsterdam.

* Tinbergen Institute. 


\section{Tinbergen Institute}

The Tinbergen Institute is the institute for economic research of the Erasmus Universiteit Rotterdam, Universiteit van Amsterdam, and Vrije Universiteit Amsterdam.

Tinbergen Institute Amsterdam

Roetersstraat 31

1018 WB Amsterdam

The Netherlands

Tel.: +31(0)205513500

Fax: $+31(0) 205513555$

Tinbergen Institute Rotterdam

Burg. Oudlaan 50

3062 PA Rotterdam

The Netherlands

Tel.: + $31(0) 104088900$

Fax: $+31(0) 104089031$

Most TI discussion papers can be downloaded at http://www.tinbergen.nl. 


\title{
Intermodal competition in the London-Paris passenger market: High-speed rail and air transport
}

\author{
Christiaan Behrens and Eric Pels \\ VU University, Department of Spatial Economics \\ De Boelelaan 1105 \\ 1081HV Amsterdam
}

\begin{abstract}
.
This paper studies inter- and intramodal competition in the London-Paris passenger market. Using revealed preference data, we estimate nested and mixed multinomial logit models to examine passenger behaviour in the London-Paris market. We present a case study on the relocation of Eurostar services from Waterloo International to St Pancras International station.

The results show that competition is present in this market. Demand is elastic, and passengers are heterogeneous in their valuation of fares and accessibility. Aviation and high-speed rail are homogenous in unobserved effects. The large market share of the Eurostar and the withdrawal of aviation alternatives indicate that competition will decline in the long-run.
\end{abstract}

Keywords: inter- and intramodal competition, nested logit, mixed logit, aviation, rail

\section{Introduction}

The passenger market between London and Paris is served mainly by two transport modes: aviation and high-speed rail (HSR). Approximately seven million passengers travelled between London and Paris in $2005 .{ }^{1}$ In this paper we analyse the modal choice of passengers travelling from London to Paris. Insight into the choice behaviour of passengers is crucial in competition analyses in the transportation sector. For instance, it is important to know to which extent low-cost airlines operating from a secondary airport, as well as a high-speed rail service operating from a centrally located station compete with full-service airlines serving a main airport in a multi-airport area. London is a multiairport area, with five international airports, four of which can be used as departure airports in the London-Paris market. Furthermore, the HSR, nowadays departing from St Pancras International station, is a travel alternative to Paris.

\footnotetext{
${ }^{1}$ Office for National Statistics (2006).
} 
Empirical analyses of passenger preferences in this market are scarce. Starkie (2002) briefly discusses intermodal competition using an example from the United Kingdom, and concludes that cross-elasticities between rail and aviation are quite high. Through a case study analysis, Steer Davies Gleave (2006) predict that the rail market share will increase in future. A lack of data on the HSR alternative is the primary reason for the dearth of empirical research relating to this specific market. To the best of our knowledge, this paper provides the first empirical analysis of competition between the HSR and aviation in the London-Paris passenger market.

In the paper we analyse how the market share of a specific travel alternative in the London-Paris passenger market depends on passenger preferences, and how a change in one of the alternatives (a shift of rail services from Waterloo International Station to St. Pancras International Station) will affect market shares. Nested logit and mixed logit models are estimated and accompanying elasticities of market shares are calculated using revealed preference data. We will discuss the consequences of the relocation of Eurostar services from Waterloo International to the St Pancras International station.

The structure of the paper is as follows. Section 2 provides an overview of the relevant literature. Section 3 introduces the data used to estimate the discrete choice models. The use of both the nested and the mixed multinomial logit models is discussed in section 4. Section 5 presents the empirical results, while direct- and cross-elasticities of demand are discussed in section 6. Conclusions and a discussion are given in section 7 .

\section{Literature}

IATA (2003) examines the opportunities for HSR in a market dominated by air traffic. Using data obtained from an internet survey among air travellers, the report concludes that HSR will be used more often if connections improve and access times to stations decrease. The first HSR between two European cities, Paris and Lyon, began operations in 1981. Park and Ha (2006) report that this HSR connection caused the passenger aviation market share to tumble from 30 to 15 percent. This was a first indication that HSR can compete strongly with air transport in medium distance transport markets. Although the London-Paris passenger market is one of the largest in Europe, no empirical evidence on competition between Eurostar and air transport is available.

Capon et al. (2003) provide an extensive overview of the literature on intermodal competition between rail and air transport for medium distance trips. The papers included in their review are based on discrete choice modelling, from multinomial logit to crossnested logit modelling. The authors discuss the modal attributes and in general, travel time, travel costs (fare), frequency, and trip purpose (business or leisure) are all included. 
Most of the papers discussed by Capon et al. (2003) use stated preference data, which highlights an important difference between intramodal and intermodal competition literature. The hypothetical and forecasting nature of the intermodal competition literature is a main reason to use stated preference data. The majority of models use linear utility functions. An exception is Mandel et al. (1994) who analyse intermodal competition between HSR and air traffic in Germany. One of their important conclusions is that the specification of the underlying utility functions, either linear or non-linear, influences the outcomes of demand forecast models.

Bhat (1997) and Koppelman and Wen (2000) examine intermodal competition in the Toronto-Montreal passenger market. Ortúzar and Simonetti (2008) and Park and Ha (2006) investigate the passenger market between Santiago and Concepción in Chile and Seoul and Deagu in South Korea, respectively. Bhat (1997) uses a revealed preference dataset from 1989 to examine passenger behaviour in the Toronto-Montreal passenger market. Besides the simple multinomial and nested logit models, Bhat estimates a covariance heterogeneity nested logit model, allowing for passenger covariance heterogeneity among nested alternatives. The estimated models reveal, via the calculated cross-elasticities of demand, that passengers are most sensitive to out-of-vehicle and invehicle travel time. Koppelman and Wen (2000) use the same dataset to illustrate that a more advanced specification of the nested logit model, the paired combinatorial logit model, alters the obtained results in terms of cross-elasticities of demand. The paired combinatorial logit model allows for more flexibility for similarity, correlation and substitution patterns between each of the alternative pairs. Using the same explanatory variables as Bhat (1997), their results reveal that the magnitude of the cross-elasticities differs between the nested logit and the paired combinatorial logit model specification. The ranked order between the explanatory variables does not change in comparison to Bhat (1997) and among the different specifications: travel time remains the most important decision variable for passengers in the Toronto-Montreal passenger market.

Ortúzar and Simonetti (2008) use mixed stated and revealed preference data to investigate passenger choice among airplane, fictitious high-speed train, regular train services, and bus alternatives in the Santiago-Concepción passenger market. They estimate nested logit models using travel time, fare, comfort, and service delay as explanatory variables for low and high income samples, respectively. No significant parameter estimations for fare and comfort are obtained. Park and Ha (2006) use stated preference techniques to forecast the market share of aviation and HSR after the introduction of the Korea Train Express (KTX) between Seoul and Deagu in 2004. Based on the survey results, the authors estimate a simple logit model and calculate crosselasticities of demand. Among others, travel time, fares and operational frequency are 
included as modal attributes. The calculated cross-elasticities show that the values for fare levels are larger in absolute terms than the values for other modal attributes. Park and Ha (2006) conclude that a significant decline of aviation demand, approximately 85 percent, can be expected as a result of the start of KTX operations.

Ivaldi and Vibes (2005) and González-Savignat (2004) investigate intermodal competition between aviation and HSR in Europe. Ivaldi and Vibes (2005) use simulation techniques, rather than revealed or stated preference techniques, to investigate inter- and intramodal competition in the Cologne-Berlin passenger market. The underlying model for their simulation is based on the nested logit model. Within this model, frequency, average fares, speed, and capacity are the explanatory variables; furthermore, a distinction is made between business and leisure passengers. The simulation results reveal that a small number of competitors is already sufficient to compel severe inter- and intramodal competition. González-Savignat (2004) investigates the effect of an HSR connection between Barcelona and Madrid (Spain) using stated preference techniques. The author estimates a binomial logit model including fares, travel time and frequency as explanatory variables to examine passenger behaviour. The results show that differences exist between groups of passengers (business and leisure), and emphasize the importance of classifying total travel time into several components: in-vehicle travel time, accessibility and frequency. González-Savignat (2004) concludes that HSR will obtain a large market share, and that travel time and costs are the competitive drivers.

We use revealed preference data in the present paper to analyse competition between HSR and aviation. A large body of literature on competition within the aviation market using revealed preference data is available. Skinner (1976), using 1974 data describing passenger behaviour in the Baltimore-Washington bi-region, estimates several multinomial logit models and accompanying elasticities of demand. Harvey (1987) investigates passenger choice of a departure airport in the multi-airport San Francisco Bay Area, using revealed preference data from a 1980 survey. Furthermore, he uses a multinomial logit model to estimate the effects of access time to the airport and relative and absolute flight frequency at each airport on the choice of passengers for one of three available airports. Different models for business and leisure passengers are estimated; this distinction between business and leisure passengers is also applied in most other studies.

Ashford and Bencheman (1987), Caves et al. (1991), Thompson and Caves (1993), and Brooke et al. (1994) in particular provide early literature of discrete choice modelling of passenger behaviour in the United Kingdom. The authors all use the same method, the multinomial logit model, to investigate passenger behaviour. Of greater interest is the fact that all the papers also include the same explanatory variables - fare, frequency and accessibility - and identify the types of travellers. Ashford and 
Bencheman (1987) and Caves et al. (1991) conclude that accessibility is the most important explanatory variable, while Thompson and Caves (1993) and Brooke et al. (1994) find that flight frequency is the most important variable in explaining choice behaviour of passengers in the United Kingdom.

Recent empirical research in this field is given in Pels et al. (2001, 2003), Hess and Polak (2005), Hess (2005), Ishii et al. (2009), and Suzuki (2007). Pels et al. (2003) estimate a nested logit model to analyse the combined airport and access mode choice of passengers departing from the San Francisco Bay Area, using revealed preference data obtained from a 1995 passenger survey. Separate models for leisure and business passengers are estimated. Average flight frequency, average fare, access time, and access costs are the explanatory variables in the model. Pels et al. (2003) conclude that access time and flight frequency are the important characteristics in the competition between airports; business travellers show higher values of time and frequency and leisure travellers are more sensitive to prices. Suzuki (2007) extends the analysis of Pels et al. (2003) by using a two-step nested logit model, the objective of which is to relax the assumption that passengers consider all combined airport-airline alternatives when choosing such a combination. Using revealed preference data from passengers originating from Iowa (USA) and access time, flight frequency and airfares as explanatory variables, the results obtained are largely similar to the studies discussed above. An important drawback of the Suzuki (2007) study is that, due to a small sample size, no distinction is made between business and leisure travellers. In another analysis, Ishii et al. (2009) uses the revealed preference dataset of Pels et al. (2003) to estimate both a conditional logit model and mixed logit model for business and leisure passenger airport-airline choice in the San Francisco Bay Area-Greater Los Angeles passenger market. Ishii et al. (2009) conclude that airport competition is mainly based on non-price characteristics, such as flight frequencies, access time, and average departure and arrival delays.

Hess and Polak (2005) also use the 1995 San Francisco Bay Area dataset to study airport choice, and estimate mixed logit models, including explanatory variables as average fare, flight frequency and access time for business and leisure passengers. The difficulty of obtaining significant fare parameters is probably due to the poor quality of the fare data. Hess and Polak (2005) also highlight that access time and flight frequencies are important determinants of the departure airport and airline choice of the passenger. The results of the mixed logit model demonstrate that sensitivity towards the explanatory variables varies significantly across passengers. Hess (2005), using 1996 revealed preference data, estimates a cross-nested logit model in order to analyse the combined airport, access mode and airline choice of leisure and business passengers. His results indicate that passenger behaviour is influenced most by access time, flight frequencies 
and scheduled flight time. Average fares are included as an explanatory variable, but are insignificant due to data limitations.

Our overview of the empirical literature on airport-airline competition focuses on relevant starting points for the current empirical research. Flight frequency, airport accessibility and average fare are important explanatory variables. However, due to data limitations it is difficult to include fares and interpret the fare-related results. In addition, our review has shown that similarities exist between the intramodal and intermodal competition literature; crucial explanatory variables - travel time, frequency and costs are the same for both kinds of research. Finally, the intermodal competition literature reveals that significant competition between HSR and air traffic is expected on medium range trips of 200 to 600 kilometres.

\section{Data}

We use the International Passenger Survey (IPS) obtained from the Office for National Statistics (2006). The IPS contains information given by a random sampling of passengers leaving the United Kingdom by air, sea or the Channel Tunnel. 250.000 faceto-face interviews are held each year. In our case the sample period runs from October 2003 up to and including October 2004. Within the IPS it is possible to identify travellers in the London-Paris market. The IPS contains personal characteristics, including gender, age, travel purpose, nationality, and county of residence or stay. Passengers also indicate the fare they paid (converted into constant 1995 British pounds) and their class of ticket. Weighting procedures ensure that the total set of passengers using an alternative in the London-Paris passenger market is representative for the passenger behaviour in that market.

Characteristics of the alternatives in the London-Paris passenger market are obtained from different sources. Flight frequencies of operating airlines are taken from OAG Market Analysis (2004). Weekly frequency and travel times of the Eurostar are obtained via its timetable valid from September 2003 onwards. Scheduled travel times for aviation alternatives are taken from three sources; scheduled flight duration is obtained from the Conducive Technology Corporation (2007); check-in times are found in Steer Davies Gleave (2006); and the average delay of flights is taken from CAA (2004). The accessibility of the four airports and the station is measured as total road distance in kilometres between the passenger's county of residence or stay and the airport.

Table 1 summarizes the market shares and weekly frequency of all available alternatives in the London-Paris passenger market during 2003-2004. The calculated market shares for each alternative - based on the IPS data - are largely the same as those 
reported by Eurostar (2004). Four airlines offered scheduled flights to Paris Charles de Gaulle (CDG), departing from four London airports. All airlines together offered 294 flights a week between London and Paris (CDG). Table 1 illustrates that within the aviation passenger market British Airways (BA) and Air France (AF) are by far the largest players, with market shares of 36 percent and 33 percent, respectively. At the airport level, the British Airports Authority (BAA) - owner of London Heathrow and London Gatwick - is clearly the dominant actor, with an aviation market share of 78 percent. The HSR alternative in the London-Paris passenger market deserves special attention. Table 1 reveals that Waterloo International station, and thereby the Eurostar, has a dominant position in the London-Paris passenger market.

Table 1 Total passengers from London to Paris (01-10-2003 until 31-10-2004)

\begin{tabular}{|c|c|c|c|c|}
\hline Mode & Airport & Passengers & $\begin{array}{l}\text { Market share (in } \\
\%)\end{array}$ & Weekly frequency \\
\hline \multirow[t]{2}{*}{$\overline{\mathrm{AF}}$} & LCY & 4498 & 0.07 & 5 \\
\hline & LHR & 700303 & 10.53 & 92 \\
\hline \multirow[t]{3}{*}{ BA } & LCY & 33959 & 0.15 & 16 \\
\hline & LGW & 249225 & 3.75 & 36 \\
\hline & LHR & 494034 & 7.43 & 73 \\
\hline $\mathrm{BD}$ & LHR & 227492 & 3.42 & 39 \\
\hline $\mathrm{U} 2$ & LTN & 422190 & 6.35 & 33 \\
\hline EUR & WAT & 4521663 & 67.96 & 94 \\
\hline Total & & 6653365 & 100 & 388 \\
\hline
\end{tabular}

$\mathrm{AF}=$ Air France, $\mathrm{BA}=$ British Airways, $\mathrm{BD}=$ British Midland Airways, U2= easyJet, Eur= Eurostar, $\mathrm{LCY}=$ London City Airport, LGW= London Gatwick, LHR= London Heathrow, LTN= London Luton, WAT= Waterloo International Station.

Table 2 indicates the number of leisure and business passengers included in the dataset for each alternative in the London-Paris passenger market in the period October 2003 up to and including October 2004. The dataset includes 2648 leisure and 1464 business passengers. In addition, table 2 shows the difference between sample market shares (after removal of incomplete observations) and total market shares (including all observations obtained from the IPS data) for each alternative. Although the magnitude of the sample market shares is largely the same as total market shares, some differences are noticeable. The main reason for this difference is that a relatively large number of Eurostar passengers did not indicate their travel class and were therefore excluded from the analysis. In addition, a relatively small number of British Airways passengers at London Heathrow are excluded due to incomplete questionnaires. 
Table 2 Sample and total market shares from London to Paris (01-10-2003 until 31-10-2004)

\begin{tabular}{l|cccccc}
\hline Alternative & Leisure & $\begin{array}{c}\text { Sample } \\
\text { market } \\
\text { share }\end{array}$ & $\begin{array}{c}\text { Total market } \\
\text { share }\end{array}$ & Business & $\begin{array}{c}\text { Sample } \\
\text { market } \\
\text { share }\end{array}$ & $\begin{array}{c}\text { Total market } \\
\text { share }\end{array}$ \\
\hline LHR-AF & 283 & 10.7 & 8.2 & 155 & 10.6 & 15.4 \\
LHR-BA & 170 & 6.4 & 3.9 & 333 & 22.7 & 12.5 \\
LHR-BD & 72 & 2.7 & 3.0 & 92 & 6.3 & 4.9 \\
LGW-BA & 56 & 2.1 & 2.2 & 49 & 3.3 & 4.1 \\
LTN-U2 & 180 & 6.8 & 6.0 & 87 & 5.9 & 6.5 \\
LCY-AF & 10 & 0.4 & 0.1 & 2 & 0.1 & 0.4 \\
WAT-EUR & 1877 & 70.9 & 76.5 & 746 & 51.0 & 56.0 \\
& & & & & & \\
Total & 2648 & 100 & 100 & 1464 & 100 & 100 \\
\hline
\end{tabular}

Table 3 Characteristics of each alternative (01-01-2003 until 31-10-2004)

\begin{tabular}{l|lllllll}
\hline Alternative & $\begin{array}{l}\text { Average fare } \\
\text { first-class }\end{array}$ & $\begin{array}{l}\text { Average } \\
\text { fare } \\
\text { second- } \\
\text { class }\end{array}$ & $\begin{array}{l}\text { Average } \\
\text { weekly } \\
\text { frequency }\end{array}$ & $\begin{array}{l}\text { Scheduled } \\
\text { in-vehicle } \\
\text { travel time }\end{array}$ & $\begin{array}{l}\text { Check- } \\
\text { in time }\end{array}$ & $\begin{array}{l}\text { Average } \\
\text { delay }\end{array}$ & $\begin{array}{l}\text { Total } \\
\text { travel } \\
\text { time }\end{array}$ \\
\hline LHR-AF & 479.12 & 165.23 & 90 & 70 & 60 & 15 & 145 \\
LHR-BA & 198.74 & 76.80 & 73 & 65 & 60 & 16 & 141 \\
LHR-BD & 170.14 & 54.21 & 35 & 70 & 60 & 20 & 150 \\
LGW-BA & 231.83 & 53.59 & 33 & 75 & 60 & 15 & 150 \\
LTN-U2 & n.a. & 40.31 & 32 & 75 & 120 & 14 & 209 \\
LCY-AF & n.a. & 182.67 & 5 & 65 & 30 & 13 & 108 \\
WAT-EUR & 124.4 & 56.9 & 94 & 160 & 30 & n.a. & 190 \\
\hline
\end{tabular}

Table 3 summarizes the transport mode characteristics of each alternative in the choice set. The accessibility variable, the road distance from the home county to each airport/station, is not included in this table because this information is different for each individual. The average (one-person return) fares are calculated in 1995 British pounds. By assumption, passengers are not permitted to choose the travel class: the travel class of the chosen alternative is assigned to the non-chosen alternative. First-class average fares cannot be calculated for LCY-AF alternative due to the lack of complete responses of first-class LCY-AF travellers. The LTN-U2 alternative is a low-cost carrier alternative and therefore first (business) class tickets are not offered. The extremely high average first-class fare for the LHR-AF alternative, relative to the other alternatives, is 
surprising. ${ }^{2}$ Another noteworthy observation is that the average first-class fare for British Airways at LGW is higher compared to the average first-class fare for British Airways at LHR, while the second-class fare for British Airways at LHR is higher compared to LGW. LHR is a popular and congested airport, which may explain the differences in second-class fares, while the differences in first-class fares seem to be caused by the relatively small sample of first-class passengers at LGH-BA. The time-related variables are all measured in minutes. The scheduled in-vehicle travel times are based on gate-togate travel times for a representative flight of the specific alternative. ${ }^{3}$ The average delay of the WAT-EUR alternative is omitted from the analysis since this information is not publicly available and therefore also has little influence on choice behaviour. The cheapest alternative in the choice set, LTN-U2, turns out to also be the slowest alternative (highest total travel time). Nevertheless, table 3 reveals considerable variation among the different alternatives of each characteristic; hence the choice set seems appropriate for the estimation of a nested logit model.

Passenger choice is influenced by personal, journey and mode characteristics. Average fare, scheduled travel time, check-in time, average delay, and road distance are all expected to show a negative effect on the utility of an individual. The opposite is expected for the frequency parameter: a larger number of flights leads to a higher utility level. We assume decreasing returns of frequency, as is common in the literature, so frequency is included in logarithmic form. According to the literature, business passengers are expected to value travel time and frequency higher compared to leisure passengers. The reverse holds for the average fare. The personal characteristics age and gender are included in the dataset; for both characteristics the expected influence on the choice of an alternative is unknown. Unfortunately, the most important personal characteristic, income, is not recorded in the IPS. Besides the parameters for mode, journey and personal characteristics, alternative specific constants will be estimated for each station/airport or airline/train alternative. These constants reflect the systematic utility not accounted for by the other explanatory variables.

\section{Model set-up}

\subsection{Nested logit model}

Following the literature on discrete choice theory and product differentiation (Anderson et al., 1992), the choice of a representative passenger for a specific alternative in the

\footnotetext{
${ }^{2} 34$ respondents combined with high fares (above £1500) seem to be the cause for this extremely high average fare.

${ }^{3}$ The most frequently chosen time-slot for each alternative, based on flight numbers, is used as the representative flight.
} 
London-Paris passenger market can be modelled using the nested multinomial logit model as depicted in Figure 1. Note that the structure of the nested logit model is based on assumptions about the correlation of unobserved effects between alternatives and should not be interpreted as the passengers' decision tree (Hensher et al., 2005). Figure 1 shows the complete set of alternatives for each traveller. The choice set is determined by including all possible alternatives in the specific period. The alternative London City Airport-British Airways is excluded because average fares could not be calculated from the available data.

Figure 1 Nested logit model structure of passengers (01-01-2003 until 31-10-2004)

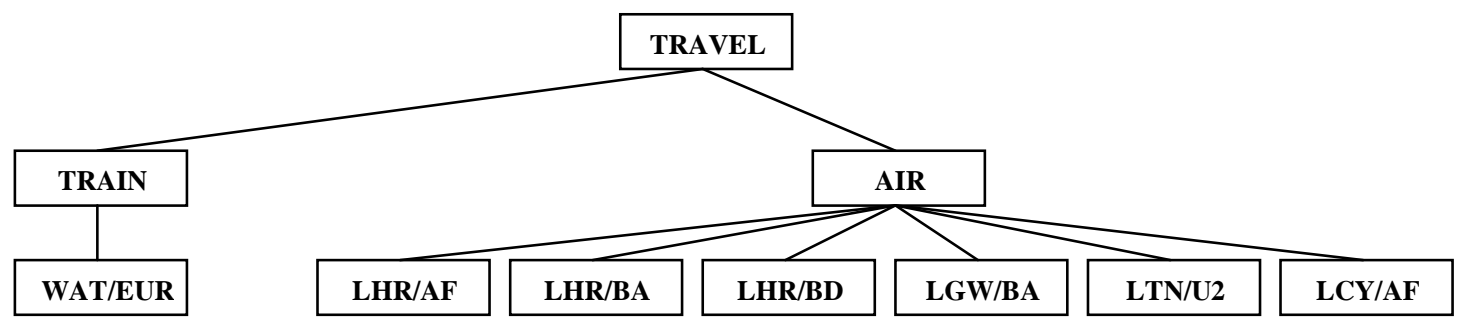

The systematic indirect utility of the lower level in the model (the alternative), $V_{i, j}$, is based on the characteristics of the chosen alternative, $j$, in the selected nest, travel by train or by air, $i$. In total, $N$ modes of transport (train or air) are available, and each offers $M$ alternative airlines/airport or rail/station combinations. The systematic indirect utility of the upper level of the nest, $V_{i}$, is based on the characteristics of the chosen mode of travel, $i$, plus the maximum expected utility derived from the chosen airline/airport or rail/station combination. This last term is referred to as the inclusive value $\left(I V_{i}\right)$. The total indirect utility function equals the systematic indirect utility plus a random utility component. Here we assume that the random utility component of the combination $(i, j)$ is independent and identically Gumbel distributed with scale parameter $\mu$, and that the random utility component of the travel mode $i$ is independent and identically distributed with the parameter $\theta$. The probability that a certain mode of travel, $i$, and airline/airport or rail/station combination, $j$, is chosen is (see e.g. Hensher et al., 2005):

$$
\begin{aligned}
& P(i, j)=P(j \mid i) P(i) \\
& P(j \mid i)=\frac{\exp \left[\mu\left(\mathrm{X}_{i, j}^{\prime} \beta\right)\right]}{\sum_{j^{\prime} \in M(i)} \exp \left[\mu\left(\mathrm{X}_{i, j^{\prime}}^{\prime} \beta\right)\right]}
\end{aligned}
$$




$$
P(i)=\frac{\exp \left[\theta\left(Z_{i}^{\prime} \gamma+\frac{1}{\mu} I V_{i}\right)\right]}{\sum_{i^{\prime} \in N} \exp \left[\theta\left(Z_{i^{\prime}}^{\prime} \gamma+\frac{1}{\mu} I V_{i^{\prime}}\right)\right]}
$$

with

$$
I V_{i}=\ln \sum_{j^{\prime} \in M(i)} \exp \left[\mu\left(\mathrm{X}_{i, j}^{\prime} \beta\right)\right]
$$

The parameters $\mu$ and $\theta$ are scale parameters, while $\theta / \mu$ as shown in equation (3) is known as the inclusive value parameter. All are estimated together with the other parameters of the nested logit model. In order to estimate the model, the $\mu$ scale parameters are scaled to one for econometric purposes (Hensher et al., 2005). Within the nested logit model, the parameters $\mu$ and $\theta$ represent the degree of heterogeneity in unobserved effects between alternatives in a nest, $\mu$, and between nests, $\theta$, respectively. If $\theta$ approaches one, the different nests become better substitutes of each other. For the model to be consistent with utility maximizing behaviour, it is required that $\theta \leq \mu$ (Hensher et al., 2005). The interpretation of this inequality is straightforward: alternatives in a specific nest are more similar than alternatives in other nests. Therefore, the scale parameter $\theta$ should lie between zero and one.

Figure 1 reveals that a degenerated alternative exists in the London-Paris passenger market. Degenerated alternatives are the only alternatives in a specific nest. The existence of degenerated alternatives in the nested logit model imposes several restrictions in the estimation of such models. The utility of degenerated cases can be specified at just one of the two levels of the nested logit model. Therefore, the variance at each level of such an alternative must be identical in order not to violate the assumption of utility maximizing behaviour. The scale parameter of the degenerated alternative and the scale parameter of the nest of that alternative are therefore restricted to being equal. Because $\mu$ is normalised to 1 for econometric purposes, this implies that the scale parameters for the nest "train" must also be normalised to 1 .

\subsection{Mixed logit model}

The mixed logit model is a highly flexible model that allows for correlation in unobserved effects, unrestricted substitution patterns, and random taste variation of individuals (Train, 2003). The assumption about rational, utility maximizing, behaviour also applies for the mixed logit model. The model structure is rather straightforward as shown in figure 2. 
Figure 2 Mixed logit model structure of passengers (01-01-2003 until 31-10-2004)

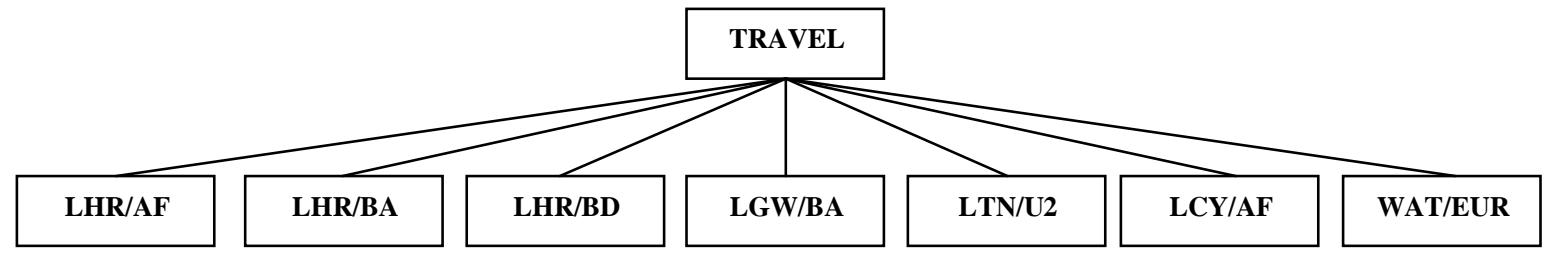

$V_{n i}=X_{n i}^{\prime} \beta_{n}+\varepsilon_{n i} \quad i=1 \ldots m$

In equation (5) the total utility function is shown. The utility of person $n$ from alternative $i$ is equal to the systematic utility, together with the person and alternative specific error term $\varepsilon_{n i}$, which is iid extreme value, as is the case in the nested logit model. In total there are $M$ alternatives present in the choice set. Note that $\beta_{n}$ is random and follows a specific distribution as shown in equation (8). The probability that person $n$ chooses alternative $i$ is denoted as:

$P_{n}(i)=\int L_{n i}(\beta) f(\beta) d \beta$

with

$L_{n i}\left(\beta_{n}\right)=\frac{e^{X_{n i}^{\prime} \beta_{n}}}{\sum_{i^{\prime} \in M} e^{X_{n i}^{\prime} \cdot \beta_{n}}}$

and

$f\left(\beta_{n}\right)=\phi(\beta \mid \mu, \sigma)$

In this case we are interested in the parameters describing the density function as presented in equation (8) instead of the parameters $\beta$, which enter the logit formulas (6) and (7). The density function of each $\beta$ can have several distributions - among them normal, lognormal, triangular, and uniform - and the describing parameters are, for example, the mean, covariance and standard deviation. 


\section{Empirical results}

\subsection{Nested logit model}

The estimation results for the nested logit model are presented in table 4 . The models for business and leisure passengers differ in the estimation of the time parameters and alternative specific constants. Each model is presented without the personal characteristics age and gender as explanatory variables, since the estimated parameters are insignificant in each model. The results are robust to changes in the unknown average delay of the Eurostar alternative. Finally, in interpreting the results, the assumptions made about fares and structure of the nested logit model are noteworthy. Since this is a revealed preference study, it is important to note that the researcher specifies the choice structure for the passengers afterwards; these strong assumptions must be kept in mind when formulating conclusions based on this study. ${ }^{4}$

Table 4 shows the results of models I and II, estimated on the basis of Figure 1. Starting with the business market, model I is theoretically and statistically correct. In other words, all parameters have the expected sign and are significant at the $99 \% /$ percent confidence level. The estimated inclusive value parameter of the AIR nest is close to one. From the estimation results we can conclude that passengers' value of time differs for different transport modes. For the business segment, the time parameter for the full service airlines is higher (in absolute terms) than the Eurostar time parameter, which is again slightly higher than the easyJet time parameter. The different valuations of travel time for full service airline and HSR may be due to the quality of service provided by each transport mode not accounted for in the estimated model.

Model II is also theoretically and statistically correct. All of the estimated parameters are significant, and have the correct sign. The included alternative-specific constants indicate that travelling from the congested LHR airport results in a disutility for the passenger relative to travelling from LTN, LCY or Waterloo station. Note that the inclusive value parameter is significantly different from zero and approaches one, which is the same result as obtained for model I. The interpretation is that, for the London-Paris passenger market, aviation and HSR alternatives are strong substitutes in unobserved effects. The estimated inclusive value parameters approaching 1 may also be interpreted as indicators that the simple multinomial logit model is more appropriate than the nested logit model. To test the overall model significance of the nested logit model compared to the restricted and the multinomial logit model, the log-likelihood ratio test can be applied. The essential log-likelihoods are also reported in table 4 . For both models the hypothesis that the nested logit model does not outperform the multinomial logit model holds true

\footnotetext{
${ }^{4}$ The models are estimated using the Limdep software package, version 4.01.
} 
and therefore can be rejected. Because the estimated coefficients are hard to interpret, direct- and cross-elasticities of demand will be calculated in section 6 .

Table 4 Estimation results for Model I and Model II

\begin{tabular}{lll}
\hline & Model I (business) & Model II (Leisure) \\
choice variables & & \\
In(frequency) & $1.3699^{*}(0.102)$ & $1.6429^{*}(0.064)$ \\
road distance & $-0.0321^{*}(0.002)$ & $-0.0243^{*}(0.001)$ \\
Fare & $-0.0050^{*}(0.001)$ & $-0.0093^{*}(0.002)$ \\
total travel time & - & $-0.0149^{*}(0.004)$ \\
total travel time FSA & $-0.0227^{*}(0.008)$ & - \\
total travel time LCC & $-0.0151^{*}(0.006)$ & - \\
total travel time TRAIN & $-0.0163^{*}(0.006)$ & - \\
LHR-AF & - & $-1.1288^{*}(0.184)$ \\
LHR-BA & - & $-2.2656^{*}(0.194)$ \\
LHR-BD & - & $-1.9980^{*}(0.210)$ \\
LGW-BA & - & $-1.4781^{*}(0.221)$ \\
& & \\
inclusive value parameter & & \\
$\theta$ AIR & $0.9536^{*}(0.026)$ & $0.9944^{*}(0.019)$ \\
$\theta$ TRAIN & 1 (FIXED) & 1 (FIXED) \\
& & \\
Observations & 1464 & -2648 \\
Log likelihood & -1831 & -2569 \\
MNL Log likelihood & -1833 & -3217 \\
Restricted Log likelihood & -2302 & \\
\hline Standard errors are given & in brackets.* &
\end{tabular}

Standard errors are given in brackets. ${ }^{*}=$ significant at 99 percent level of confidence.

\subsection{Mixed logit model}

Table 5 depicts the output for the mixed logit estimations for model III (business) and model IV (leisure). As with the nested logit model case, different utility specifications are used for the business and leisure samples. Since the mixed logit model is a non-closed form model, the models are simulated using 1000 Halton draws. The BFGS algorithm is used to solve the nonlinear optimization of the log likelihood. The estimated models are robust to changes in the number and type of draws and the algorithm used. For identification purposes, at least one attribute is held as a non-random parameter (Train, 2003). A key decision in mixed logit modelling is the decision of the type of distribution attached to each of the random parameters. Normal, log-normal, uniform, and triangular distributions are all suitable ways to define the distribution. Theoretically, if the a priori sign of the attribute is known, a lognormal distribution is preferred. Unfortunately, a lognormal-specified distribution of the attributes results in a non-converging model in this case; we therefore apply the normal distribution. Several alternative specifications are estimated for both passenger groups, including alternative specific constants, other random parameters, specified distributions, and personal characteristics. The inclusion of personal characteristics results in non-convergence, while defining random parameters 
for frequency and (total) travel time results in non-significant estimation of the standard deviation of these random parameters. We report in table 5 the mean as well as the standard deviation for the random parameters in both models.

\section{Table 5 Estimation results for Model III and Model IV}

\section{Model III (Business) Model IV (Leisure)}

Choice variables

Random parameters

$\begin{array}{lll}\text { Mean of (road distance) } & -0.0416 *(0.003) & -0.0291^{*}(0.002) \\ \text { Std. dev. of (road distance) } & 0.0295^{*}(0.005) & 0.0163^{*}(0.006) \\ \text { Mean of (fare) } & -0.0169 *(0.002) & -0.0456^{*}(0.008) \\ \text { Std. dev. of (fare) } & 0.0131 *(0.002) & 0.0216^{*}(0.004)\end{array}$

Non-random parameters

$\operatorname{Ln}$ (frequency)

$1.9489 *(0.169) \quad 1.8335 *(0.100)$

Total travel time

$-0.0071 *(0.003)$

$-0.0519 *(0.009)$

ASC Train

$-0.1421(0.200)$

ASC LHR-AF

ASC LHR-BA

$-$

ASC LHR-BD

ASC LGW-BA

$-$

$-3.3103 *(0.324)$

$-3.4284 *(0.399)$

ASCLGW-BA

$-$

$-3.0229 *(0.436)$

\begin{tabular}{lcc} 
Observations & 1464 & 2648 \\
Log likelihood & -1807 & -2516 \\
MNL log likelihood & -1836 & -2541 \\
Restricted log likelihood & -2849 & -5153 \\
\hline
\end{tabular}

Standard errors are given in brackets. ${ }^{*}=$ significant at 99 percent level of confidence.

The estimated parameters for the business and leisure passenger models are all significant at the 99 percent confidence level. In both models each of the estimated parameters has the expected sign. The only exceptions are the alternative-specific constants for the train alternative and the LHR-AF alternative in the business and leisure model, respectively. Using the log-likelihood ratio test, we conclude that models III and IV outperform the restricted as well as the multinomial logit model. Since these mixed logit estimations do not account for nested structures as do models I and II, it is not correct to perform the same log-likelihood ratio test on the nested logit-versus the mixed logit specification. However, a quick comparison between the log-likelihood ratios indicates that the mixed logit model is preferred.

The results show that the parameter of road distance to departure nodes is normally distributed over the passengers, with a mean of -0.04 (business) and -0.03 (leisure), and a standard deviation of 0.03 (business) and 0.02 (leisure). Note that, as a consequence, seven percent of business passengers and four percent of leisure passengers 
has a preference for travelling longer distances to the departure node. This is exactly why a lognormal distribution is preferred in the case of an a priori known sign.

\section{Calculating direct- and cross-elasticities of demand}

\subsection{Direct elasticity of demand}

The direct elasticity of demand measures the effect of a one percent change in the attribute of an alternative on the total probability of choosing the specific alternative. In the case of the nested logit model, the direct elasticity of demand with respect to attribute $X$ is:

$$
\frac{\partial P(i, j)}{\partial X_{i, j}} \frac{X_{i, j}}{P(i, j)}=X_{i, j} \beta(1-P(j \mid i)+\theta P(j \mid i)(1-P(i)))
$$

Note that this is not the elasticity of demand. The total aggregate demand in the LondonParis passenger market is assumed to be inelastic: an increase/decrease in the probability that a specific alternative will be chosen results in a decrease/increase in the choice probability of all other alternatives. In section 6.2 these cross-elasticities of demand are further examined. The elasticity as defined in equation (9) is a point elasticity of demand and is evaluated by aggregating the individual elasticities using the individual choice probabilities as weights (Hensher et al., 2005).

In the case of the mixed logit model, the direct elasticity of demand, which has the same interpretation, is defined as:

$$
\frac{\partial P_{n}(i)}{\partial X_{n i}} \frac{X_{n i}}{P_{n}(i)}=\frac{X_{n i}}{P_{n}(i)} \int \beta L_{n i}(\beta)\left(1-L_{n i}(\beta)\right) f(\beta) d \beta
$$

As with the model itself, the resulting elasticity of demand has no closed form. Using the same 1000 Halton draws as used in the model estimation, the elasticity is calculated and the average is taken for each individual. We apply the same weighting procedure here as we used in the nested logit model. If attribute $X$ is stated in logarithmic form, as is the case with frequency, equations (9) and (10) are multiplied by $1 / X$.

Table 6 shows the direct elasticities of demand for all models for the attributes frequency, fare and (total) travel time. The elasticities of demand differ between the nested logit and the mixed logit specification. It is unexpected and important to note that the pattern of the elasticity differs between the specifications case. The direct elasticity 
with respect to the time attribute show that business passengers are inelastic for all alternatives in the mixed logit estimation, while they elastic in the nested logit model. ${ }^{5}$

The differences between the leisure and business models are also surprising. The frequency elasticities of demand for business passengers are smaller than those of leisure passengers, as reported in model II, which is unexpected. However, the differences between the travel time elasticities are larger and of the expected sign: business passengers value travel time higher than leisure travellers. In the mixed logit estimations, leisure passengers are in general more sensitive to changes in the attributes fare and travel time. While the result for the fare elasticity is expected, the result for the travel time elasticity is not.

Table 6 Direct elasticities of demand in the London Paris passenger market with respect to frequency, fare and time for Model I -IV

\begin{tabular}{|c|c|c|c|c|c|c|c|c|c|c|c|c|}
\hline & \multicolumn{2}{|c|}{ Model I (business) } & \multicolumn{4}{|c|}{ Model II (leisure) } & \multicolumn{3}{|c|}{ Model III (business) } & \multicolumn{2}{|c|}{ Model IV (leisure) } & \multirow[b]{2}{*}{ time } \\
\hline & frequency & fare & time & frequency & fare & time & frequency & fare & time & frequency & fare & \\
\hline LHR-AF & 1.16 & -0.89 & -2.78 & 1.42 & -1.39 & -1.87 & 1.23 & -0.73 & -0.67 & 1.01 & -2.32 & -4.20 \\
\hline LHR-BA & 1.07 & -0.43 & -2.50 & 1.52 & -0.77 & -1.94 & 1.40 & -1.17 & -0.73 & 1.66 & -3.08 & -6.62 \\
\hline LHR-BD & 1.27 & -0.41 & -3.13 & 1.59 & -0.60 & -2.16 & 1.75 & -1.35 & -0.99 & 1.75 & -2.73 & -7.45 \\
\hline LGW-BA & 1.24 & -0.42 & -3.07 & 1.56 & -0.59 & -2.12 & 1.47 & -0.95 & -0.83 & 1.63 & -2.43 & -6.92 \\
\hline LTN-U2 & 1.05 & -0.16 & -2.43 & 1.37 & -0.31 & -2.59 & 1.16 & -0.48 & -0.90 & 1.34 & -1.57 & -7.94 \\
\hline LCY-AF & 1.36 & -0.91 & -2.44 & 1.64 & -1.69 & -1.60 & 1.90 & -0.53 & -0.77 & 1.05 & -2.28 & -5.37 \\
\hline WAT-EUR & 0.51 & -0.14 & -1.16 & 0.43 & -0.15 & -0.74 & 0.68 & -0.41 & -0.47 & 0.62 & -0.56 & -2.20 \\
\hline
\end{tabular}

When we examine the direct elasticities of demand, it is surprising and unexpected to observe that the frequency elasticity of demand is larger than one for all aviation alternatives in both estimated models. In a theoretical model, Pels et al. (2000) find that the frequency elasticity needs to be smaller than 1 in order to maximize profits. ${ }^{6}$ There are two possible explanations for this finding: first, that the frequency of service may be correlated with variables not included in the analysis, such as the availability of frequent-flyer programs or peak-hour flights. Because these variables are not available, there may be a missing variable bias. But in a short-haul market these effects may be less important. A second possible explanation is the fact that airport capacity is constrained at London airports. Airlines compete based on price and frequency. The frequency offered by an airline in the market from London to Paris is restricted by the total capacity of the airports. When demand in a specific market is larger than the capacity allocated to this market, we expect that the elasticity of market share with respect to frequency will be relatively high because airlines cannot increase their frequency. In other words, we

\footnotetext{
${ }^{5}$ This is contrary to the expectations: the literature points out that business travellers are sensitive to travel time.

${ }^{6}$ The second order condition for profit maximization in a discrete choice model, which includes the frequency in logarithmic form, reduces to the requirement that frequency elasticity should be smaller than 1. If this condition is not met an increase in the number of flights results in a more than proportional increase in demand.
} 
expect that the profit maximizing frequency exceeds the current frequency determined by competition and airport capacity. Figure 3 shows the results of a simulation exercise to check this argument. For four alternatives in this market (LHR-AF, LHR-BA, LHR-BD, and LTN-U2) the elasticity of demand with respect to frequency $(\varepsilon)$ indeed increases when frequency is decreased and decreases when frequency is increased. Note that in other markets where there is less competition with HSR and/or low-cost carriers, the frequency elasticity may be below 1 (cf. Pels et al., 2003).

Figure 3. Direct elasticity of demand with respect to frequency pattern for four alternatives: LHRAF, LHR-BA, LHR-BD and LTN-U2 ( $\mathrm{P}=$ probability of choosing the stated alternative, and $\varepsilon=$ elasticity of demand).

LHR-AF (90 flights)

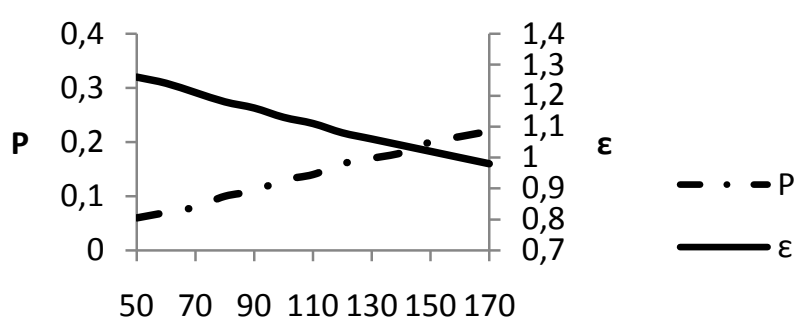

Number of flights

LHR-BD (35 flights)

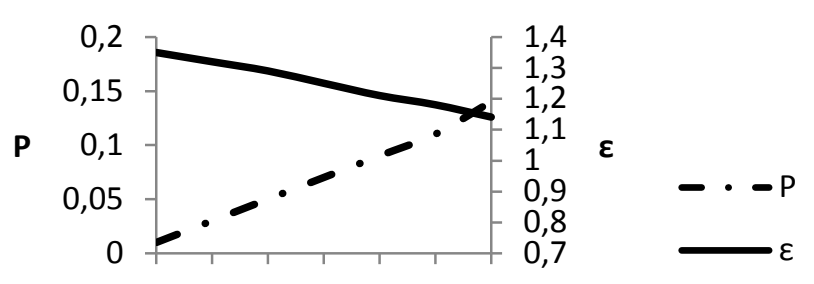

10203040506070

Number of flights
LHR-BA (73 flights)

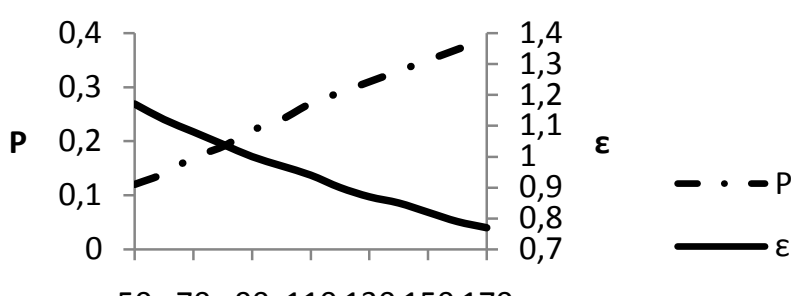

Number of flights

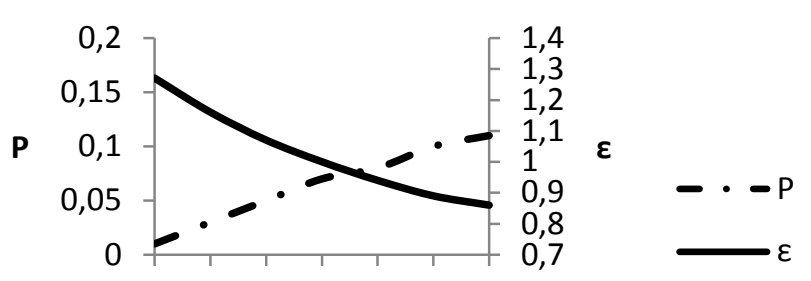

$102030 \quad 40506070$

Number of flights

\subsection{Cross-elasticity of demand}

The cross-elasticity of demand given in equation (11) measures the effect of a one percent change in the attribute of an alternative (not $\mathrm{i}$, not $\mathrm{j}$ ) on the probability $\mathrm{P}(\mathrm{i}, \mathrm{j})$ in the nested logit model specification. 


$$
\frac{\partial P(i, j)}{\partial X_{-i,-j}} \frac{X_{-i,-j}}{P(i, j)}=-\theta \beta X_{-i,-j} P(-j \mid-i) P(-i)
$$

The equivalent cross-elasticity of demand in the mixed logit specification is defined as:

$$
\frac{\partial P_{n}(i)}{\partial X_{n-i}} \frac{X_{n-i}}{P_{n}(i)}=-\frac{X_{n-i}}{P_{n}(i)} \int \beta L_{n i}(\beta) L_{n-i}(\beta) f(\beta) d \beta
$$

The elasticities as defined in equations (11) and (12) are point elasticities of demand and are evaluated by aggregating the individual elasticities using the individual choice probabilities as weights (Hensher et al., 2005). If attribute $X$ is stated in logarithmic form, as is the case with frequency, equations (11) and (12) are multiplied by $1 / X$. As with the direct elasticity of demand case in equation (10), the elasticity shown in equation (12) has a non-closed form and can only be calculated using simulated probabilities. The same 1000 Halton draws are used to simulate these elasticities.

To determine the effect of a change in the level of the attribute of the Eurostar alternative on the aviation alternatives, we calculate cross-elasticities of demand. According to economic theory, cross-elasticities should be smaller (in absolute terms) than direct elasticities of demand. Table 7 reveals that this is in general the case for the London-Paris passenger market. ${ }^{7}$ The cross-elasticities for fare are higher for leisure travellers, as expected: leisure travellers react stronger than business travellers to fare changes. Leisure travellers are more sensitive to frequency and travel time, contrary to expectations. The most important attribute for both market segments is travel time, followed by frequency and fare. In general, all aviation alternatives compete equally strongly with the HSR: the hypothesis that the LCC competes more with HSR than other airlines is not supported by the results.

\begin{tabular}{|c|c|c|c|c|c|c|c|c|c|c|c|c|}
\hline & \multicolumn{2}{|c|}{ Model I (business) } & \multicolumn{4}{|c|}{ Model II (leisure) } & \multicolumn{3}{|c|}{ Model III (business) } & \multicolumn{2}{|c|}{ Model IV (leisure) } & \multirow[b]{2}{*}{ time } \\
\hline & frequency & fare & time & frequency & fare & time & frequency & fare & time & frequency & fare & \\
\hline LHR-AF & -0.60 & 0.15 & 1.36 & -1.08 & 0.35 & 1.87 & -0.52 & 0.10 & 0.37 & -0.73 & 0.58 & 3.99 \\
\hline LHR-BA & -0.63 & 0.19 & 1.44 & -1.11 & 0.41 & 1.92 & -0.78 & 0.54 & 0.56 & -1.18 & 1.72 & 6.39 \\
\hline LHR-BD & -0.63 & 0.19 & 1.44 & -1.12 & 0.42 & 1.93 & -0.81 & 0.67 & 0.58 & -1.24 & 2.08 & 6.74 \\
\hline LGW-BA & -0.65 & 0.18 & 1.48 & -1.13 & 0.40 & 1.95 & -0.67 & 0.45 & 0.48 & -1.20 & 1.96 & 6.50 \\
\hline LTN-U2 & -0.49 & 0.10 & 1.12 & -0.99 & 0.31 & 1.71 & -0.55 & 0.35 & 0.39 & -1.03 & 1.79 & 5.64 \\
\hline LCY-AF & -0.72 & 0.15 & 1.66 & -1.17 & 0.37 & 2.02 & -0.79 & 0.07 & 0.57 & -0.76 & 0.47 & 4.13 \\
\hline
\end{tabular}

Table 7. Cross-elasticities of demand with respect to frequency, fare and time.

The cross-elasticities of demand are based on a change at WAT-EUR.

\footnotetext{
${ }^{7}$ The cross-elasticities of demand as shown in table 7 should be interpreted as follows: a 1 percent increase in the fare of the Eurostar alternative results in a 0.15 percent increase in the market share of the LHR-AF alternative.
} 
Compared to existing studies about intermodal competition (Bhat, 1997; Koppelman and Wen, 2000; Park and Ha, 2006), the figures shown in the table 7 are rather high. Bhat (1997) reports cross-elasticities of demand based on a change in the attribute of the rail service alternative. The cross-elasticity of demand with respect to frequency, measured in departures per day, as reported by Bhat (1997) is around -0.03 for business travellers, which is considerably lower compared to our results. Koppelman and Wen (2000) report cross-elasticities of demand in the same order of magnitude as Bhat (1997), while Park and Ha (2006) find a cross-elasticity of demand with respect to frequency of -0.17 . The cross-elasticity of demand with respect to fare equals 1.8 according to Park and Ha (2006), while Bhat (1997) shows a figure of 0.1. Our results for the cross-elasticity of demand with respect to fare are therefore in-between the results found in the literature. The obtained cross-elasticities of demand with respect to travel time are considerably higher compared to the figures reported by Bhat (1997): he reports a cross-elasticity of demand for business passengers around 0.4 .

The resulting cross-elasticities of demand reported in table 7 are, in general, larger than those found in the literature. These cross-elasticities are specific to the change in the HSR alternative in the London Paris market. Note, however, that in this particular market the rail alternative has a rather extraordinary position. In section 6.1 we indicated that the airlines have difficulty in maximizing their profits because the HSR has a market share of roughly $50 \%$ for business and $75 \%$ for leisure passengers. Airlines compete with an imperfect substitute, and need to offer relatively high frequencies in order to attract passengers.

\subsection{Case study: the relocation of Eurostar services}

Our empirical results are used to analyse the impact of the relocation of Eurostar services from Waterloo International to St Pancras International station in November 2007. The relocation resulted from the opening of the High Speed 1 railway track linking the UK rail network to the European HSR network. Moreover, St Pancras International station offers many direct rail connections to national and metropolitan destinations compared to the Waterloo International station. Both the increase in accessibility and the decrease in average travel time will raise the systematic utility of HSR travellers. Using the results obtained here, only the change in travel time can be subjected to further analysis. The parameter estimations of the mixed logit models (models III and IV) are used here to forecast the change in the market share.

The opening of the High Speed 1 railway track reduces average travel time from London to Paris by 20 minutes. Given the original travel time of 190 minutes, a 20 minute reduction is equal to an approximate 10.5 percent decrease of travel time. As a 
result, the estimated market share of the Eurostar has increased by roughly 20 percent, from 71 to 85 percent in the leisure passenger market. For the business passenger market the increase is smaller (as shown by the low cross-elasticity of demand); the market share rises by 6 percent to 54 percent. The increase of the Eurostar market share coincides with a decrease in market share for all other alternatives. Within the air business passenger market, LCY-AF and LHR-BD are most affected due to Eurostar travel time reduction, whereas in the leisure air passenger market, LHR-BD and LGW-BA are most affected. We suggest that the effects of the new High Speed 1 railway track are perhaps underestimated; it is expected that the opening of the line will attract new Eurostar customers in the London-Paris passenger market who had not previously travelled between London and Paris.

\section{Conclusion}

We have analysed intermodal competition in the London-Paris market; travellers can choose between high-speed rail (HSR), conventional airlines and low-cost airlines, as well as among five departure points in London. The empirical results show that HSR is a competitor for both conventional and low-cost airlines. The alternatives LHR-BD, LGWBA and LCY-AF are no longer available between London and Paris Charles De Gaulle, which implies that conventional airlines are pulling out of a market where they encounter strong competition from HSR. Note that our results support this; the frequency elasticities are larger than 1, and indicate that profits cannot be maximized in these markets.

In order to test whether the preferences of the passengers are homogenous over the sample, we specified a mixed logit model. The results show that the preferences of accessibility and fare are random parameters. The effect of including random parameters in terms of elasticities is rather high: demand becomes more elastic if we account for heterogeneity among passengers. The mixed logit results are preferred for theoretical and empirical reasons.

We found no evidence that low-cost carriers compete more with HSR than other airlines in the London-Paris market. Even though the empirical analysis focussed on direct flight passengers (i.e. passengers connecting to other flights were excluded), the results hint at interesting policy issues. Paris Charles de Gaulle is well integrated into a high-speed rail network. HSR is becoming the dominant mode in the London-Paris market. If air-rail integration is developed further at Paris Charles de Gaulle, this airport may also become a relevant transfer point for intercontinental passengers departing from London: St. Pancras station is centrally located compared to, for instance, London Heathrow. Furthermore, London Heathrow, which is not a central point in a high-speed 
rail network, suffers increasingly from congestion, so that it has to deal with several competitive disadvantages.

Competition analysis in the air transport industry is an important issue in the United Kingdom given that the British Airport Authority (BAA) operates some of the major airports in London. This paper has shown that, in markets where HSR is a viable alternative, it will offer severe competition to both low-cost and conventional airlines. Moreover, HSR alters the competitive position of BAA airports in the intercontinental markets as described above. Competition analysis involving the aviation sector should therefore not be limited to a single mode.

Further empirical research is necessary to validate the results obtained in this study. The combined revealed and stated preference data analysis, as performed by Ortúzar and Simonetti (2008), can overcome the traditional drawbacks of revealed preference studies; that is, the lack of quality in fare data and the definition of the individual choice set.

\section{References}

Anderson, S. P., De Palma, A., \& Thisse, J.-F. (1992) Discrete Choice Theory of Product Differentiation. Cambridge, MA: The MIT Press.

Ashford, N., \& Bencheman, M. (1987) Passengers' Choice of Airport: An Application of the Multinomial Logit Model. Transportation Research Record, 1147, 1-5.

Bhat, C. R. (1997) Covariance Heterogeneity in Nested Logit Models: Econometric Structure and Application to Intercity Travel. Transportation Research Part B: Methodological, 31(1), 11-21.

Brooke, A. S., Caves, R. E., \& Pitfield, D. E. (1994) Methodology for Predicting European Short-Haul Air Transport Demand from Regional Airports: An Application to East Midlands International Airport. Journal of Air Transport Management, 1(1), 37-46.

CAA, Economic Regulation Group (ERG) (2004) Annual 2003 Punctuality Statistics. Retrieved 15-05, 2007, from http://www.caa.co.uk/docs/33/2003_ANNUAL_PUNCTUALITY_STATISTICS. $\underline{\mathrm{PDF}}$

Capon, P., Longo, G., \& Santori, F. (2003) Rail vs. Air Transport for Medium Range Trips. ICTS, Nova Gorica, 1-11.

Caves, R. E., Ndoh, N. N., \& Pitfield, D. E. (1991) Route Choice Modelling Applied to the Choice between Mature Airports and Emergent Airports in Their Shadow. 
Paper presented at the 31st Regional Science Association European Congress, Lisbon.

Conducive Technology Corporation (2007) Historical Flight Report: Online Flight Stats. Retrieved 15-05, 2007, from http://www.flightstats.com

Eurostar (2004) Fly Eurostar. Marketing Society 2004 Entry, Retrieved 01-05, 2007, from http://www.marketing-society.org.uk/downloads/awards/Eurostar_Entry.pdf

González-Savignat, M. (2004) Competition in Air Transport: The Case of the HighSpeed Train. Journal of Transport Economics and Policy, 38, 77-107.

Harvey, G. (1987) Airport Choice in a Multiple Airport Region. Transportation Research Part A: General, 21(6), 439-449.

Hensher, D. A., Rose, J. M., \& Greene, W. H. (2005) Applied Choice Analysis: A Primer. Cambridge: Cambridge University Press.

Hess, S. (2005) Analysing Air-Travel Choice Behaviour in the Greater London Area. Paper presented at the 45th Congress of the European Regional Science Association Amsterdam.

Hess, S., \& Polak, J. W. (2005) Mixed Logit Modelling of Airport Choice in MultiAirport Regions. Journal of Air Transport Management, 11(2), 59-68.

IATA, International Air Transport Association (2003) Air/Rail Intermodality Study. Hounslow: Air Transport Consultancy Services.

Ishii, J., Jun, S., \& Van Dender, K. (2009) Air Travel Choices in Multi-Airport Markets. Journal of Urban Economics, 65(2), 216-227.

Ivaldi, M., \& Vibes, C. (2005) Intermodal and Intramodal Competition in Passenger Rail Transport. Discussion Paper Series 0265-8003 Centre for Economic Policy Research, London.

Koppelman, F. S., \& Wen, C.-H. (2000) The Paired Combinatorial Logit Model: Properties, Estimation and Application. Transportation Research Part B: Methodological, 34(2), 75-89.

Mandel, B., Gaudry, M., \& Rothengatter, W. (1994) Linear or Nonlinear Utility Functions in Logit Models? The Impact on German High-Speed Rail Demand Forecasts. Transportation Research Part B: Methodological, 28(2), 91-102.

OAG Market Analysis, OAG Worldwide (2004) World Airways Guide. Dunstable: OAG. 
Office for National Statistics, Social and Vital Statistics Division (2006) International Passenger Survey 2005 (Vol. 5th Edition): Essex: UK Data Archive.

Ortúzar, J. D., \& Simonetti, C. (2008) Modelling the Demand for Medium Distance Air Travel with the Mixed Data Estimation Method. Journal of Air Transport Management, 14(6), 297-303.

Park, Y., \& Ha, H.-K. (2006) Analysis of the Impact of High-Speed Railroad Service on Air Transport Demand. Transportation Research Part E: Logistics and Transportation Review, 42(2), 95-104.

Pels, E., Nijkamp, P., \& Rietveld, P. (2000) Airport and Airline Competition for Passengers Departing from a Large Metropolitan Area. Journal of Urban Economics, 48(1), 29-45.

. (2001) Airport and Airline Choice in a Multiple Airport Region: An Empirical Analysis for the San Francisco Bay Area. Regional Studies, 35(1), 1-9.

. (2003) Access to and Competition between Airports: A Case Study for the San Francisco Bay Area. Transportation Research Part A: Policy and Practice, 37(1), 71-83.

Skinner, R. E. (1976) Airport Choice: An Empirical Study. Transportation Engineering Journal, 102(4), 871-882.

Starkie, D. (2002) Airport Regulation and Competition. Journal of Air Transport Management, 8(1), 63-72.

Steer Davies Gleave (2006) Air and Rail Competition and Complementarity. Luxembourg: Office for Official Publications of the European Communities.

Suzuki, Y. (2007) Modeling and Testing the 'Two-Step' Decision Process of Travelers in Airport and Airline Choices. Transportation Research Part E: Logistics and Transportation Review, 43(1), 1-20.

Thompson, A., \& Caves, R. (1993) The Projected Market Share for a New Small Airport in the North of England. Regional Studies, 27(2), 137-147.

Train, K. E. (2003) Discrete Choice Methods with Simulation (First ed.) Cambridge: University Press. 